\title{
Reduction of nickel oxide particles by hydrogen studied in an environmental TEM
}

\author{
Q. Jeangros - T. W. Hansen - J. B. Wagner • \\ C. D. Damsgaard · R. E. Dunin-Borkowski • \\ C. Hébert · J. Van herle $\cdot$ A. Hessler-Wyser
}

Received: 14 June 2012/ Accepted: 29 October 2012/Published online: 28 November 2012

(C) Springer Science+Business Media New York 2012

In situ reduction of nickel oxide $(\mathrm{NiO})$ particles is performed under 1.3 mbar of hydrogen gas $\left(\mathrm{H}_{2}\right)$ in an environmental transmission electron microscope (ETEM). Images, diffraction patterns and electron energy-loss spectra (EELS) are acquired to monitor the structural and chemical evolution of the system during reduction, whilst increasing the temperature. $\mathrm{Ni}$ nucleation on $\mathrm{NiO}$ is either observed to be epitaxial or to involve the formation of randomly oriented grains. The growth of $\mathrm{Ni}$ crystallites and the movement of interfaces result in the formation of pores within the $\mathrm{NiO}$ grains to accommodate the volume shrinkage associated with the reduction. Densification is then observed when the sample is nearly fully reduced. The reaction kinetics is obtained using EELS by monitoring changes in the shapes of the $\mathrm{Ni} \mathrm{L}_{2,3}$ white lines. The activation energy for $\mathrm{NiO}$ reduction is calculated from the

Electronic supplementary material The online version of this article (doi:10.1007/s10853-012-7001-2) contains supplementary material, which is available to authorized users.

Q. Jeangros $(\bowtie) \cdot C$. Hébert · A. Hessler-Wyser

Interdisciplinary Centre for Electron Microscopy, Ecole

Polytechnique Fédérale de Lausanne, Lausanne, Switzerland

e-mail: quentin.jeangros@epfl.ch

T. W. Hansen - J. B. Wagner · C. D. Damsgaard

Center for Electron Nanoscopy, Technical University

of Denmark, Lyngby, Denmark

R. E. Dunin-Borkowski

Ernst Ruska-Centre for Microscopy and Spectroscopy with Electrons and Peter Grünberg Institute, Jülich Research Centre, Jülich, Germany

J. Van herle

Industrial Energy Systems Laboratory, Ecole Polytechnique

Fédérale de Lausanne, Lausanne, Switzerland
EELS data using both a physical model-fitting technique and a model-independent method. The results of the modelfitting procedure suggest that the reaction is described by Avrami models (whereby the growth and impingement of $\mathrm{Ni}$ domains control the reaction), in agreement with the ETEM observations.

\section{Introduction}

Nickel oxide $(\mathrm{NiO})$ reduction and the subsequent $\mathrm{Ni}$ behaviour in hydrogen gas $\left(\mathrm{H}_{2}\right)$ are of practical importance in the fields of catalysis [1-5], ore reduction to produce metallic Ni [6-9] and solid oxide fuel cells (SOFCs), for which it determines the structure of the electronic conductor on the anode side during operation [10, 11]. Despite extensive coverage in the literature since the study of Benton and Emmett in 1924 [12], several questions remain, notably regarding the reduction kinetics and subsequent structural evolution of $\mathrm{NiO}$ in a reducing atmosphere at high temperature.

Richardson et al. [13], who studied $\mathrm{NiO}$ reduction using in situ X-ray diffraction, described the reaction as follows: (i) $\mathrm{H}_{2}$ first dissociates on two $\mathrm{Ni}$ atoms surrounding an oxygen vacancy [4] (the presence of such a vacancy leads to an increase in the adsorption energy of $\mathrm{H}_{2}$, which in turn reduces the energy barrier to break the $\mathrm{H}-\mathrm{H}$ bond [14]); (ii) adsorbed $\mathrm{H}$ atoms diffuse to $\mathrm{NiO}$ reaction centres; (iii) rupture of $\mathrm{Ni}-\mathrm{O}$ bonds and desorption of $\mathrm{H}_{2} \mathrm{O}$ occurs; (iv) nucleation and growth of $\mathrm{Ni}$ clusters take place; (v) $\mathrm{H}_{2}$ dissociates directly on the metallic clusters once their size is sufficient; and (vi) the reaction rate increases autocatalytically as the metal clusters grow into Ni crystallites. The presence of $\mathrm{H}_{2} \mathrm{O}$ on the surface slows down the reaction by a factor that depends on the sample geometry. The authors 
obtained an activation energy for $\mathrm{NiO}$ reduction in $\mathrm{H}_{2}$ of $85.6 \mathrm{~kJ} / \mathrm{mol}$. Other values in the literature vary by over an order of magnitude, between 10 and $150 \mathrm{~kJ} / \mathrm{mol}$ (summarized for work before 2003 in Ref. [13]), with more recent

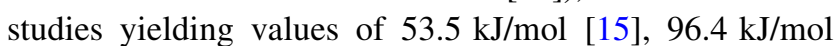
[16], 91.8-94.5 kJ/mol [17] and $15 \mathrm{~kJ} / \mathrm{mol}$ [18]. The lack of consistency between the $\mathrm{NiO}$ samples that have been studied in terms of chemistry and microstructure, characterization techniques and other experimental parameters may explain the wide scatter in these results. Furthermore, different physical models have been used to describe the kinetics of $\mathrm{NiO}$ reduction [19], including Avrami (growth and impingement of domains) [20-23], pseudo-first order [13], shrinking core (describing the formation of a porous Ni scale surrounding a shrinking NiO domain) [24, 25], the Evans-Szekely grain model (agglomeration of grains, each undergoing a shrinking core reduction) [26] and a thermomechanical approach [27]. The consistency of some of these models with the description of how NiO transformed into $\mathrm{Ni}$ was verified ex situ after the sample was transferred inertly from the reaction chamber into a microscope [25, 26].

Recent advances in environmental transmission electron microscopy (ETEM) allow the determination of nanostructural and kinetic information at the same time, giving new details about the mechanisms of gas-solid reactions. In particular, Sharma [28] showed that time- and temperature-resolved data, obtained from observations made under a gas atmosphere inside an ETEM, could be used to obtain reaction rates and to understand process kinetics. Moreover, this technique has been applied to problems in catalysis [29-31], semiconductor nucleation [32], growth kinetics [33] and redox cycling of a Ni-based SOFC anode [34]. ETEM is used here to correlate $\mathrm{NiO}$ reduction kinetics with structural changes occurring at the nanoscale, providing new insight into the mechanisms of $\mathrm{NiO}-\mathrm{H}_{2}$ interactions at elevated temperature.

\section{Experimental details}

\section{Materials}

A commercial $\mathrm{NiO}$ powder from JT Baker ${ }^{\mathrm{TM}}(\mathrm{NiO}>99.0$ wt\% with $\mathrm{Co}, \mathrm{Fe}, \mathrm{Pb}, \mathrm{Si}, \mathrm{Na}, \mathrm{S}$ and $\mathrm{Zn}$ as the main impurities), which is often used in Ni-based SOFC anodes, was studied in the present work. Diffraction using visible light yielded an average particle size of $990 \mathrm{~nm}$, with the smallest particles being less than $50 \mathrm{~nm}$ in size, whilst $\mathrm{X}$-ray diffraction gave an average crystallite size of $\sim 100$ nm (using a PANalytical X'Pert PRO diffractometer and Scherrer's formula [35]).
Electron microscopy

\section{Structural changes and reduction kinetics in the ETEM}

In order to prepare samples for electron microscopy, a small quantity of $\mathrm{NiO}$ powder was put into solution in isopropanol and immersed in an ultrasonic bath for $30 \mathrm{~min}$ to break up the agglomerates and to disperse the powder. As the particles need to be smaller than $\sim 200 \mathrm{~nm}$ to be electron transparent in a $300 \mathrm{kV}$ TEM, the solution was left to decant for a few minutes. A few drops were then taken from the surface of the liquid to select only the smallest particles. These drops of solution were dispersed onto copper grids covered in a continuous silicon dioxide film $\left(\mathrm{Cu}-\mathrm{SiO}_{2}\right)$ and mounted in a Gatan 652 double-tilt heating holder once the solvent had evaporated.

In situ reduction was performed in an FEI Titan ETEM operated at $300 \mathrm{kV}$, in which a differential pumping system allows a gaseous atmosphere to be introduced into the microscope column. A description of the microscope used in this study is given in Ref. [36].

$\mathrm{H}_{2}$ was introduced into the environmental cell at a flow rate of $2 \mathrm{ml}_{\mathrm{N}} / \mathrm{min}$, resulting in a pressure of $1.3 \mathrm{mbar}$ at the sample. The specimen was then heated to $250{ }^{\circ} \mathrm{C}$, as no reaction occurred below this temperature in the ETEM [34]. The temperature was kept constant for 30 min to reduce thermal drift. At this point, three different ramping procedures were started to approximate linear heating rates of 2, 4 and $7{ }^{\circ} \mathrm{C} / \mathrm{min}$. Fig. 1 shows the three different temperature profiles. At each step, the temperature was kept constant for 4-5 min (depending on the heating rate) to perform the measurements. With a selected area aperture inserted, a $12-\mu \mathrm{m}^{2}$ region of interest was typically characterized by acquiring a low magnification image, a diffraction pattern and a core-loss electron energy-loss spectrum (EELS; recorded in diffraction mode for 1-2 min using an energy

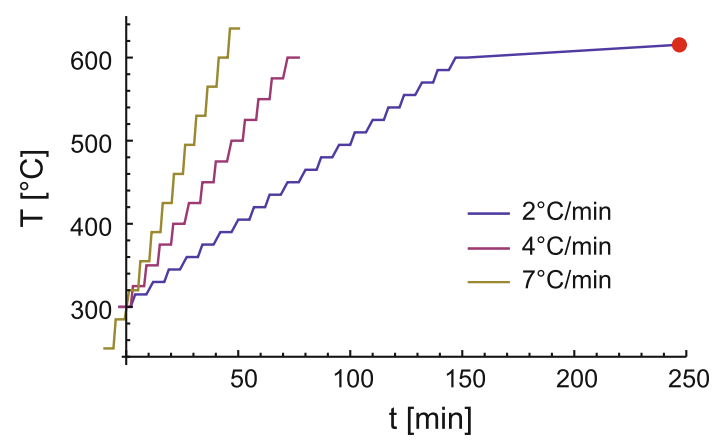

Fig. 1 Time and temperature parameters used to approximate constant heating rates. A set of measurements (involving the acquisition of an image, a diffraction pattern and an EEL spectrum) was performed at each step. The red dot indicates when a Ni electron energy-loss reference spectrum was acquired (see text for details) 
range of 500-900 eV). In order to maintain the overall heating rate, the temperature was then increased quickly by 15,25 or $35^{\circ} \mathrm{C}$ over 1 or $2 \mathrm{~min}$ to maintain an equivalent heating rate of 2,4 or $7^{\circ} \mathrm{C} / \mathrm{min}$, respectively, up to a maximum temperature of $600{ }^{\circ} \mathrm{C}$. The region of interest for each experiment was chosen so that it contained a similar $\mathrm{NiO}$ structure and a similar number of particles compared to other specimens. Each region was selected to be in the centre of the TEM grid and in the centre of a grid square to ensure a constant temperature difference $\Delta T$ between the observed area and the thermocouple, which was welded onto the outside of the furnace. This value of $\Delta T$ was assumed to be on the order of a few degrees due the thermal conductivity of the $\mathrm{H}_{2}$ gas [37] and the small distance between the thermocouple and the region of interest $(<3 \mathrm{~mm})$. The uncertainties in the temperature measurements were therefore estimated to be $\pm 5{ }^{\circ} \mathrm{C}$ for the three experiments. An electron dose rate of $\sim 365 \mathrm{e}^{-} \mathrm{nm}^{-2} \mathrm{~s}^{-1}$ was chosen as a compromise between beam damage and sufficient EELS signal over each measurement sequence. This value was kept the same for each kinetic experiment, with the region of interest imaged constantly over the length of each experiment.

The sample that had been reduced at $2{ }^{\circ} \mathrm{C} / \mathrm{min}$ up to $600{ }^{\circ} \mathrm{C}$ was then kept at a constant furnace current for $100 \mathrm{~min}$, with the resulting temperature increasing to $615^{\circ} \mathrm{C}$ over this time, to observe further structural changes and to fully reduce the $\mathrm{NiO}$ to metallic $\mathrm{Ni}$.

\section{In situ scanning and high-resolution transmission electron microscopy}

In order to identify the detailed characteristic structural changes occurring during the low magnification experiments, complementary studies were performed, involving the acquisition of scanning TEM (STEM) and high-resolution TEM (HRTEM) images of $\mathrm{NiO}$ during reduction in $\mathrm{a}_{2}$ atmosphere. The same $\mathrm{NiO}$ powder was dispersed using the same procedure onto gold grids supporting a porous $\mathrm{SiO}_{2}$ film (holey $\mathrm{Au}-\mathrm{SiO}_{2}$ ), mounted in a Philips single-tilt heating holder and plasma cleaned for $7 \mathrm{~min}$ before performing in situ reduction in the ETEM (1.3 $\mathrm{mbar}$ of $\mathrm{H}_{2}$ at $\left.2 \mathrm{ml}_{\mathrm{N}} / \mathrm{min}\right)$. Instead of using $\mathrm{Cu}$ grids with continuous $\mathrm{SiO}_{2}$ films, holey $\mathrm{Au}-\mathrm{SiO}_{2}$ grids were used to perform HRTEM in thin $\mathrm{NiO}$ areas located over the holes in the $\mathrm{SiO}_{2}$ film. After thermal drift stabilization, the temperature was kept constant until the structural evolution of $\mathrm{NiO}$ was judged to be negligible. The temperature was then increased by one current step (corresponding to $5-10{ }^{\circ} \mathrm{C}$ ) up to a final value of $600{ }^{\circ} \mathrm{C}$. The electron dose rate was varied during these complementary experiments, but kept to a minimum value, which still allowed the acquisition of images with a sufficient electron count over 0.5-1 s (depending on the thermal drift).
$\mathrm{NiO}$ reduction kinetics from electron energy-loss spectroscopy

EELS measurements record the change in the kinetic energy of an incident electron after it has passed through and interacted with a sample [38]. This analytical technique can be used to provide chemical and structural information about the sample. Here, EEL spectra were acquired during the three linear heating rate experiments to determine the reaction kinetics from changes in the shapes of the $\mathrm{Ni} \mathrm{L}_{2,3}$ white lines, which are associated with energy losses induced by the transitions of atomic electrons from $2 p_{3 / 2}$ and $2 p_{1 / 2}$ core states to empty $3 d$ states, which hybridize with oxygen $2 p$ orbitals in an oxide [39, 40]. The shape of the ionization edge, and in particular the ratio between the $\mathrm{L}_{2}$ and $\mathrm{L}_{3}$ lines (branching ratio), depends on the oxidation state.

The spectra (acquired from a $12-\mu \mathrm{m}^{2}$ area) contained the oxygen $\mathrm{K}$ edge $(532 \mathrm{eV})$, which is dominated by contributions from the $\mathrm{SiO}_{2}$ support, and the $\mathrm{Ni}(\mathrm{O})$ white lines $\left(\mathrm{L}_{3}\right.$ at $855 \mathrm{eV}$ and $\mathrm{L}_{2}$ at $872 \mathrm{eV}$ ) [41]. Spectra acquired during the three experiments were aligned by cross-correlation. Principal component analysis was then used to reduce noise [42, 43]. The first 15 principal components were used, with the remaining components assumed to contain only noise. Gatan Digital Micrograph ${ }^{\mathrm{TM}}$ software [44] was used for background subtraction, using a power law fitted over an energy range of $100 \mathrm{eV}$ before the $\mathrm{L}_{3}$ edge.

The spectra were not deconvoluted to remove plural scattering, as the specimen thickness remained approximately the same within each chosen area during a heating experiment and the thickness was not homogeneous over the recorded area.

The white lines contain contributions from both intense transitions to $3 \mathrm{~d}$ bound states and less intense transitions to the continuum [45]. The latter contributions can be subtracted before the white line ratio is calculated to provide information about the valency of the transition metal [40, 46, 47]. Rez et al. [48] stated that the number of holes in the $3 \mathrm{~d}$ band is the same for $\mathrm{Ni}$ and $\mathrm{NiO}$ and that the ratio of integrated white line intensity to that of the continuum stays constant when $\mathrm{NiO}$ is reduced to $\mathrm{Ni}$. Furthermore, as the primary goal of this work is to determine the speed of the $\mathrm{NiO}$ reduction reaction, i.e. its kinetics, a simplified technique was used (as in Ref. [49] and the maximumintensity method in Ref. [40]), whereby the continuum contribution was not subtracted and the $\mathrm{L}_{3}$ and $\mathrm{L}_{2}$ edges were fitted using a polynomial function or a Gaussian and then integrated using $2 \mathrm{eV}$ windows centred on their respective maxima. The $I\left(\mathrm{~L}_{3}\right) / I\left(\mathrm{~L}_{2}\right)_{T}$ ratios at each temperature step $T$ were then normalized using the experimental $\mathrm{Ni}$ and $\mathrm{NiO}$ reference ratios $\left(I\left(\mathrm{~L}_{3}\right) / I\left(\mathrm{~L}_{2}\right)_{\mathrm{Ni}}\right.$ and $I\left(\mathrm{~L}_{3}\right) /$ 
$I\left(\mathrm{~L}_{2}\right)_{\mathrm{NiO}}$, respectively) to obtain the degree of conversion $\alpha$ during the reduction process, with a $\mathrm{Ni}$ experimental reference obtained by keeping the sample reduced at $2{ }^{\circ} \mathrm{C} / \mathrm{min}$ for $100 \mathrm{~min}$ at $600-615^{\circ} \mathrm{C}$ in $1.3 \mathrm{mbar}$ of $\mathrm{H}_{2}$ (red dot in Fig. 1)

$\alpha_{T}=\frac{\left[I\left(\mathrm{~L}_{3}\right) / I\left(\mathrm{~L}_{2}\right)_{\mathrm{NiO}}\right]-\left[I\left(\mathrm{~L}_{3}\right) / I\left(\mathrm{~L}_{2}\right)_{T}\right]}{\left[I\left(\mathrm{~L}_{3}\right) / I\left(\mathrm{~L}_{2}\right)_{\mathrm{NiO}}\right]-\left[I\left(\mathrm{~L}_{3}\right) / I\left(\mathrm{~L}_{2}\right)_{\mathrm{Ni}}\right]}$

An alternative technique based on changes in the shapes of the $\mathrm{Ni} \mathrm{L}_{2,3}$ white lines was also used to determine $\alpha$. Each experimental spectrum acquired at a temperature $T$ was fitted to $\mathrm{NiO}$ and $\mathrm{Ni}$ experimental reference spectra (spectrum $_{\mathrm{NiO}}$ and spectrum $_{\mathrm{Ni}}$, respectively) using a multiple linear least squares algorithm (MLLS) [48]. The factors $a$ and $b$, which minimize the least square error between the experimental spectrum and that calculated using the reference spectra were obtained for each temperature step $T$.

spectrum $_{T}=a_{T}$ spectrum $_{\mathrm{NiO}}+b_{T}$ spectrum $_{\mathrm{Ni}}$

$\alpha_{T}=\frac{b_{T}}{a_{T}+b_{T}}$

The measured values of $\alpha$, determined as a function of temperature $T$, describe the speed of the reaction, i.e. the kinetics of $\mathrm{NiO}$ reduction. The rate of a single step solidstate reaction is usually described in terms of a function $f$ that depends on the reaction model and on the temperature $T$ (in $\mathrm{K}$ ) according to an Arrhenius function, in the form [19]

$\frac{d \alpha}{d t}=A e^{-\left(E_{a} / R T\right)} f(\alpha)$

where $E_{a}$ is the activation energy (in $\mathrm{J} \mathrm{mol}^{-1}$ ), $A$ a preexponential factor related to the collision frequency $\left(\mathrm{min}^{-1}\right)$, and $R$ the universal gas constant $\left(8.314 \mathrm{~J} \mathrm{~mol}^{-1} \mathrm{~K}^{-1}\right)$.

For a linear heating rate experiment, Eq. 4 can be rewritten by introducing the heating rate $\beta=\mathrm{d} T / \mathrm{d} t$ in the form

$\frac{d \alpha}{d T}=\frac{A}{\beta} e^{-\left(E_{a} / R T\right)} f(\alpha)$

The activation energy can be obtained using the Kissinger method, whereby the derivative with temperature of Eq. 5 takes a value of 0 at a temperature $T_{\max }$, at which the reaction rate reaches a maximum value [50]. Based on measurements of the change in $T_{\max }$ with heating rate and assuming that the value of $\alpha$ at the peak position does not change with heating rate, it is possible to extract the activation energy. Plotting $\ln \left(\beta / T_{\max }^{2}\right)$ against $1 / T_{\max }$ for different heating rates $\beta$ should result in a straight line with a slope of $-E_{a} / R$.
Alternatively, after separating the variables and replacing the temperature integral on the left by a third rational approximation (with $x=E_{a} / R T$ ) [51], Eq. 5 yields the expression

$$
\begin{aligned}
g(\alpha) & =\int_{0}^{\alpha} \frac{d \alpha}{f(\alpha)}=\frac{A}{\beta} \int_{T_{o}}^{T} e^{-\left(E_{a} / R T\right)} d T \\
& =\frac{A}{\beta} \frac{E_{a}}{R}\left[\frac{e^{-x}}{x} \frac{x^{2}+10 x+18}{x^{3}+12 x^{2}+36 x+24}\right]_{x_{0}}^{x}
\end{aligned}
$$

The integral solid-state reaction model $g(\alpha)$ describes mathematically how a solid reactant $(\mathrm{NiO})$ is transformed into a solid product $(\mathrm{Ni})$. The different possible models can be categorized as follows: nucleation and domain growth (power law, Avrami, Prout and Tompkins autocatalytic model), geometrical contraction (shrinking cylinder, sphere), diffusion (1-D, 2-D, 3-D Ginstling-Brounshtein, 3-D Jander) and reaction order (zero-, first-, second-, thirdorder). These different models are listed in Ref. [19]. By means of Eq. 6 and a chosen reaction model $g(\alpha), \alpha$ can be simulated for a set of kinetic parameters $E_{a}$ and $A$ [52]. Here, a Nelder-Mead procedure was used to minimize the least squared difference between the experimental and calculated values of $\alpha$ for a specific reaction model [53]. As $E_{a}$ and $A$ are invariant with heating rate, the three $\alpha-T$ profiles obtained experimentally using EELS for heating rates of 2, 4 and $7^{\circ} \mathrm{C} / \mathrm{min}$ were fitted simultaneously by using a least squares minimization algorithm to yield values of $E_{a}$ and $A$. The different fits were then compared to yield the most likely triplets of the reaction model, $A$ and $E_{a}$.

\section{Experimental results}

$\mathrm{NiO}$ structural evolution during in situ reduction

Figure 2 shows a selection of TEM images and corresponding electron diffraction patterns, which illustrate the characteristic changes that occur in the $\mathrm{NiO}$ microstructure during a $2{ }^{\circ} \mathrm{C} / \mathrm{min}$ ramp from 300 to $600{ }^{\circ} \mathrm{C}$.

Figure 2a shows results obtained from initial $\mathrm{NiO}$ particles recorded at $300{ }^{\circ} \mathrm{C}$ in 1.3 mbar of $\mathrm{H}_{2}$. At $405{ }^{\circ} \mathrm{C}$, $\sim 50 \mathrm{~min}$ after the start of the ramp at $2{ }^{\circ} \mathrm{C} / \mathrm{min}$ (Fig. 2b), pores form within larger particles (arrowed), whilst smaller particles shrink (see the region marked with a circle). $\mathrm{Ni}$ reflections appear in the diffraction pattern (200 reflections are marked in Fig. 2). Figure 2c shows that at $525{ }^{\circ} \mathrm{C}$, reduction continues and the grains restructure, with the pores starting to disappear. In Fig. 2d, the smaller Ni grains have disappeared in favour of the larger grains (see the region marked with a circle), whilst fewer $\mathrm{Ni}$ reflections appear in the diffraction pattern (see the Ni 200 ring). 

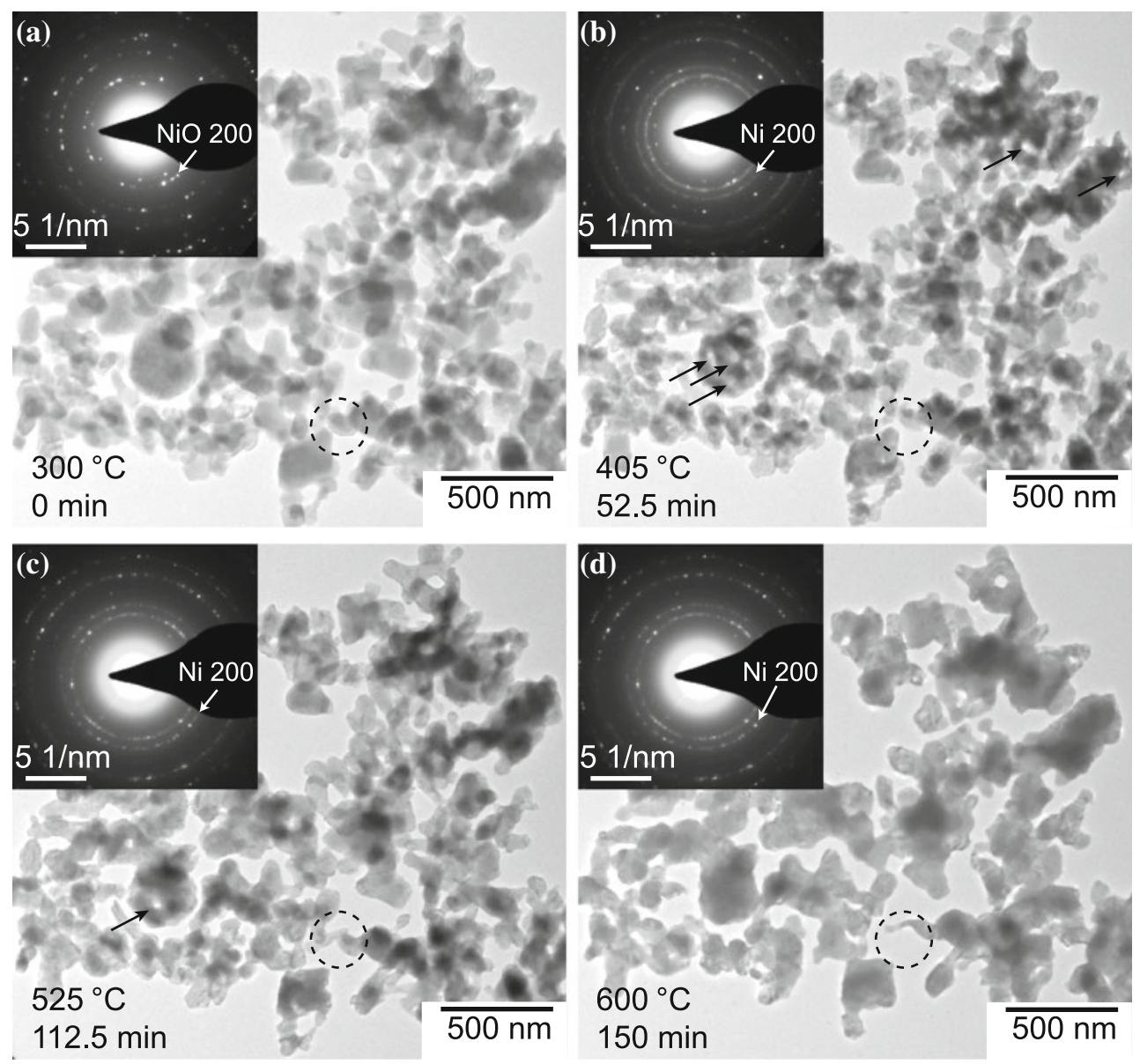

Fig. 2 Sequence of TEM images and electron diffraction patterns acquired in situ in the ETEM in 1.3 mbar of $\mathrm{H}_{2}$ during NiO reduction, for an overall heating rate of $2{ }^{\circ} \mathrm{C} / \mathrm{min}$

Images acquired at 4 and $7{ }^{\circ} \mathrm{C} / \mathrm{min}$ exhibit similar behaviours, with temperature delays of $\sim 50$ and $\sim 90^{\circ} \mathrm{C}$, respectively.

Figure 3 shows radial profiles of the electron diffraction patterns acquired at a heating rate of $2{ }^{\circ} \mathrm{C} / \mathrm{min}$. The evolution of the $\mathrm{NiO} 220$ and $\mathrm{Ni} 200$ reflections, which do not overlap with other reflections, demonstrates the simultaneous disappearance of $\mathrm{NiO}$ and appearance of $\mathrm{Ni}$, as shown in Fig. 3b, c. All of the observed reflections can be indexed as either $\mathrm{Ni}$ or $\mathrm{NiO}$.

High-resolution TEM images show that the nucleation of $\mathrm{Ni}$ on $\mathrm{NiO}$ already takes place at temperatures below $400{ }^{\circ} \mathrm{C}$ in the ETEM (Fig. 4). Ni domains grow on the surfaces of $\mathrm{NiO}$ grains and can be identified by their lattice fringes using fast Fourier transforms (FFT) of the highresolution TEM images, as $\mathrm{Ni}$ and $\mathrm{NiO}$ have different lattice spacings. They are both face-centred cubic (fcc) structures with unit cell parameters of $0.368 \mathrm{~nm}$ for $\mathrm{Ni}$ and $0.418 \mathrm{~nm}$ for $\mathrm{NiO}$. In some areas, $\mathrm{Ni}$ nucleation is nearly epitaxial on the initial $\mathrm{NiO}$ grain, whilst elsewhere the orientation relationship is more complex (Fig. 4).
The nucleation step could not be observed for every $\mathrm{NiO}$ particle due to thermal drift associated with each increment of temperature. The grains were seen to evolve into an inhomogeneous structure (Fig. 5) by the displacement of interfaces, inducing particle shrinkage and pore creation within larger particles to accommodate the volume loss due to the removal of oxygen ( $\sim 40 \%$ [54]).

Some $\mathrm{NiO}$ grains react at a lower temperature when compared with other particles. A sequence of STEM HAADF images (Fig. 6) shows that some grains become irregular due to the removal of oxygen, whilst other grains are left unchanged and have not reacted yet (see Fig. 6b).

$\mathrm{Ni}$ nanoparticles are also observed on the surfaces of larger $\mathrm{Ni}(\mathrm{O})$ particles at elevated temperature $\left(500{ }^{\circ} \mathrm{C}\right.$, Fig. 7).

A careful investigation of diffraction patterns acquired at $600{ }^{\circ} \mathrm{C}$ (e.g. the pattern in Fig. $2 \mathrm{~d}$ and the corresponding radial profile in Fig. $3 b$ ) shows that some $\mathrm{NiO}$ is still present at temperatures close to $600{ }^{\circ} \mathrm{C}$. Figure 8 shows that $\mathrm{NiO}$ is still present within particles that contain mainly $\mathrm{Ni}$, with Moiré patterns forming where the two overlap. 
Fig. 3 a Radially averaged profiles of electron diffraction patterns acquired during in situ reduction at $2{ }^{\circ} \mathrm{C} / \mathrm{min}$. b The $\mathrm{NiO} 220$ reflections disappear, as shown after removing a power law background, whilst c the Ni 200 reflections appear simultaneously as the temperature increases
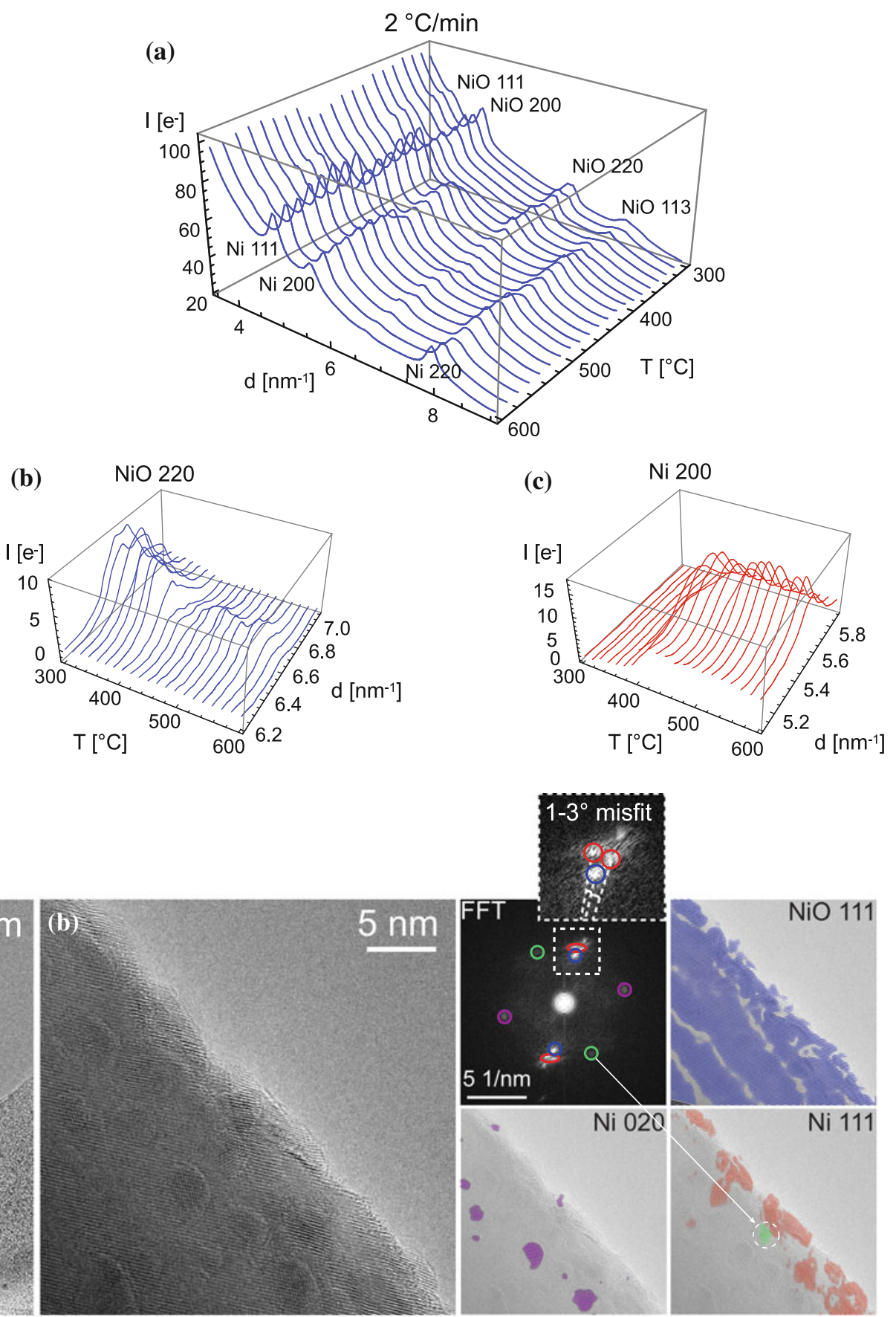

Fig. $4 \mathrm{Ni}$ nucleation on $\mathrm{NiO}$ observed using ETEM at $370{ }^{\circ} \mathrm{C}$ in 1.3 mbar of $\mathrm{H}_{2}$, showing a nucleation on the whole surface and $\mathbf{b}$ an HRTEM image of the nucleation stage, alongside FFT and inverse

When exposed to $\mathrm{H}_{2}$ at temperatures above $600{ }^{\circ} \mathrm{C}$ for $100 \mathrm{~min}$, Ni was observed to tend towards full reduction, with the structure evolving to minimize its surface energy, as shown in Fig. 9. Pores that had been created at a lower temperature to accommodate the volume shrinkage associated with reduction were observed to disappear. Larger grains were found to grow and densify, whilst smaller grains also disappeared.
FFT (pseudo-dark-field) images (coloured, with the HRTEM image added as a background). The inset illustrates the angular misfit observed between the NiO 111 and Ni 111 reflections in the FFT

\section{EELS kinetic analysis}

EEL spectra recorded at a heating rate of $2{ }^{\circ} \mathrm{C} / \mathrm{min}$ and the resulting reaction kinetics are illustrated in Fig. 10. The fits of the experimental spectra obtained using the MLLS technique had correlation coefficients above 0.98. Reduction is observed to proceed quickly until the remaining $\mathrm{NiO}$ fraction reaches a level of about $40 \%$ (Fig. 10). The 

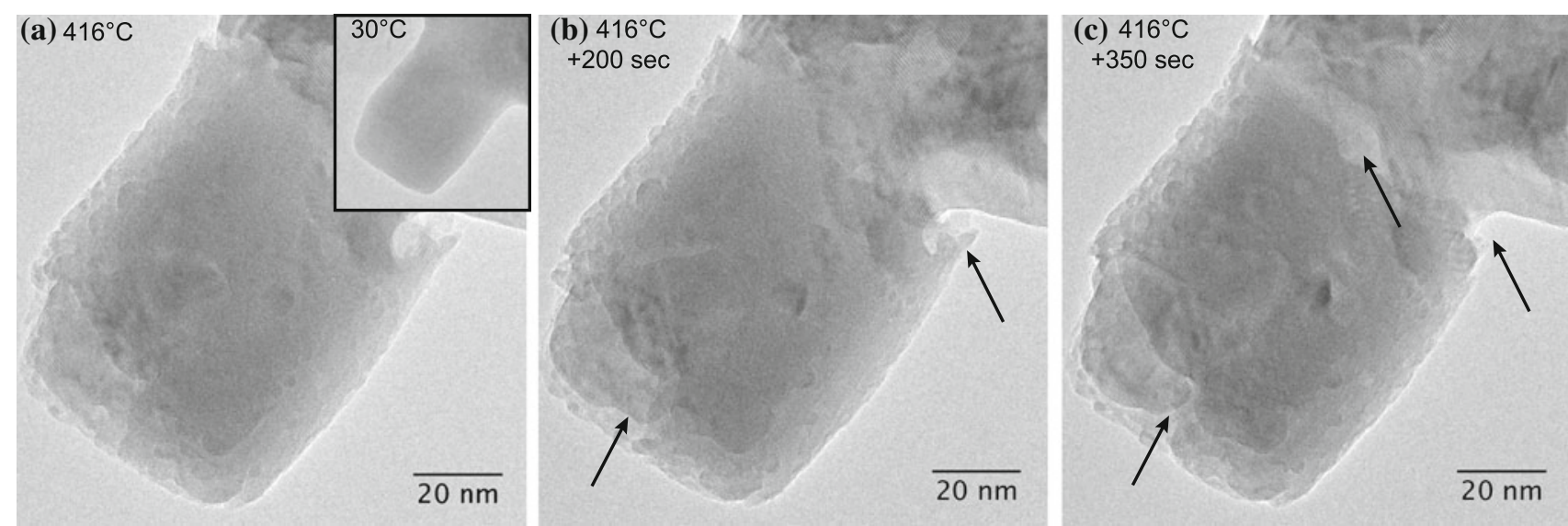

Fig. $5 \mathrm{Ni}(\mathrm{O})$ evolution at $416{ }^{\circ} \mathrm{C}$ in $1.3 \mathrm{mbar}$ of $\mathrm{H}_{2}$ into an inhomogeneous structure. Interfaces change as a function of time, as indicated by arrows
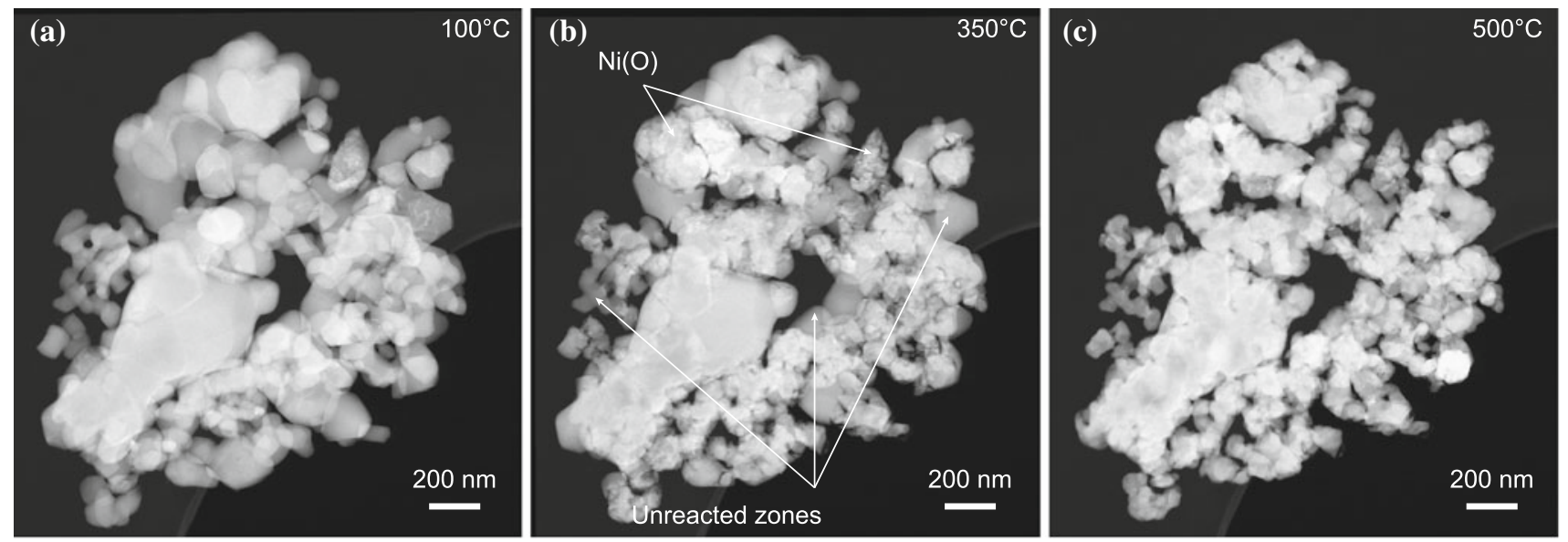

Fig. 6 STEM HAADF image sequence of a $\mathrm{Ni}(\mathrm{O})$ agglomerate of grains recorded at different temperatures in $1.3 \mathrm{mbar}^{\circ} \mathrm{H}_{2}$

reaction then slows down, with full reduction achieved only at temperatures above $600{ }^{\circ} \mathrm{C}$ (also confirmed using electron diffraction; see Fig. 9d).

Figure 11 shows the conversion fraction $\alpha$ (equivalent to the fraction of $\mathrm{Ni}$ ) measured for heating rates of 2, 4 and $7{ }^{\circ} \mathrm{C} /$ min obtained using the three different methods. The graphs show that the reaction is delayed when the heating rate is increased.

The reaction rate is observed to decrease when $\alpha$ exceeds 0.6 , independent of the heating rate. This behaviour influences the mathematical analysis of the kinetics, as the reaction rate appears to be controlled by more than one mechanism over the full range $0 \leq \alpha \leq 1$. As NiO reduction is known to be autocatalytic [13], a physical process that is not linked to the chemical reaction, but more likely to the experimental parameters (see discussion below), is thought to reduce the rate of the reaction at a high conversion fraction. The transition is relatively sharp between the first kinetic regime $(0 \leq \alpha \leq 0.6)$ and the second kinetic regime $(\alpha>0.6)$. In order for Eq. 4 to be valid, it is assumed that the two mechanisms that control the reaction occur in succession and that they do not both affect the reaction rate at the start of the reaction, with the first part of the $\alpha-T$ curve determined solely by chemical resistance to $\mathrm{NiO}$ reduction.

In order to use the Kissinger method, the $\alpha-T$ curves that are obtained for different heating rates must be differentiated to extract the temperature at which the reaction rate is the greatest. As only a small number of experimental data points are obtained using EELS, an empirical function similar to that used in Ref. [56] was used to fit the measurements within the range $(0 \leq \alpha \leq \varepsilon)$, where $\varepsilon$ corresponds to the value of $\alpha$ at the plateau observed in Fig. 11 $(\sim 0.65)$, in the form

$\alpha=\varepsilon\left(1-e^{\frac{-\left(T-T_{0}\right)^{-\gamma}}{\beta \eta}}\right)$

where $\eta$ and $\gamma$ are fitting parameters and $T_{0}$ is the onset temperature. The best-fitting curves to the data are shown in Fig. $11\left(\mathrm{R}^{2}>0.99\right)$. Each curve was then differentiated to determine the temperature at which the reaction rate is 
greatest, $T_{\max }$. Table 1 lists the values of $T_{\max }$ obtained using the three different methods, the value of $\alpha$ at this temperature $\alpha_{\max }$ and the activation energy for $\mathrm{NiO}$ reduction obtained using the Kissinger method. Measures of the goodness of the linear fits used to determine $E_{a}$ are expressed in terms of the coefficient $\mathrm{R}^{2}$. Temperatures are indicated in degrees Celsius, although the calculations were performed in Kelvin.

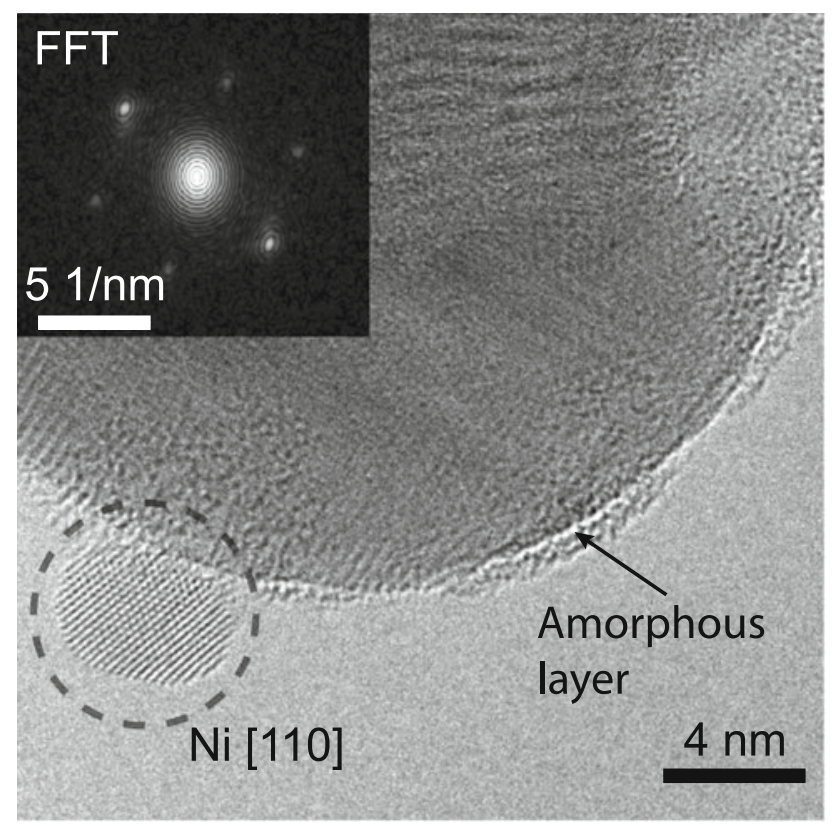

Fig. 7 HRTEM image acquired in 1.3 mbar of $\mathrm{H}_{2}$ from a Ni nanoparticle oriented along [110] (indexed by its FFT) on the surface of a $\mathrm{Ni}(\mathrm{O})$ grain at $500{ }^{\circ} \mathrm{C}$. Some blurring is present due to thermal drift. An amorphous layer (probably carbon) is present on the surface of the larger $\mathrm{Ni}(\mathrm{O})$ grain
An alternative approach involved the use of values of $g(\alpha), E_{a}$ and $A$ to model the data acquired at heating rates of 2, 4 and $7{ }^{\circ} \mathrm{C} / \mathrm{min}$ using a least squares minimization algorithm. Only points up to values of $\alpha \leq 0.6$ were fitted using the least squares algorithm, in order to discount points that were affected by the external processes.

As few experimental data points are available, this method cannot be used to distinguish between similar reaction models and the results must be interpreted with caution. Nevertheless, the fitting procedure appears to indicate qualitatively how $\mathrm{NiO}$ is transformed into Ni. Only the nucleation models (involving descriptions of growth of domains by power law, Avrami or Prout-Tompkins derivations) yield realistic fits to the measurements with reasonable activation energy and pre-exponential factor values. As only the acceleratory phase of the $\alpha-T$ curve is fitted, the power law descriptions of the nucleation process yield good results. However, these models do not describe the termination of the reaction process, as there is no restriction on the growth of the seeds [19]. The Prout-Tompkins model describes an autocatalytic reaction, in which the formation of the product results in the evolution of cracks and/or dislocations at the reaction interface (in the form of a branching process) [19]. For $\mathrm{NiO}$ reduction, the autocatalytic behaviour results from the fact that $\mathrm{H}_{2}$ adsorption and dissociation occur preferentially on $\mathrm{Ni}$, with subsequent transfer to $\mathrm{NiO}$ [13]. Our ETEM observations, in combination with an assessment of the physical meaning of the models, suggest that the Avrami mathematical derivations, which are referred to as A2 in Ref. [19] (1-D or 2-D growth of nuclei), A3 (2-D or 3-D growth of nuclei) and A4 (3-D growth of nuclei), appear to describe the transformation of these $\mathrm{NiO}$ particles well when compared to the other kinetic models tested (Fig. 12).
Fig. 8 HRTEM image acquired in 1.3 mbar of $\mathrm{H}_{2}$, its FFT and corresponding inverse FFTs (pseudo-dark-field images), showing $\mathrm{NiO}$ within $\mathrm{Ni}$ grains at $600{ }^{\circ} \mathrm{C}$. Moiré patterns are visible in the regions where $\mathrm{Ni}$ and $\mathrm{NiO}$ are superimposed

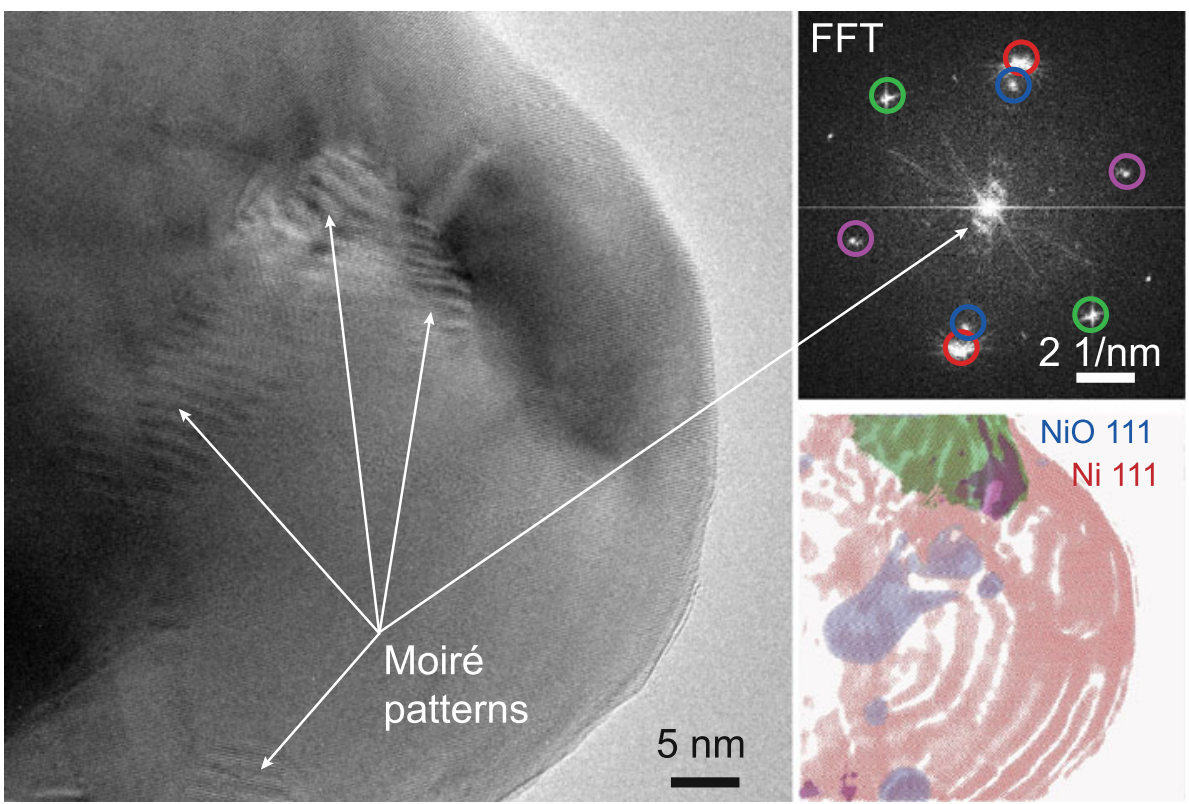




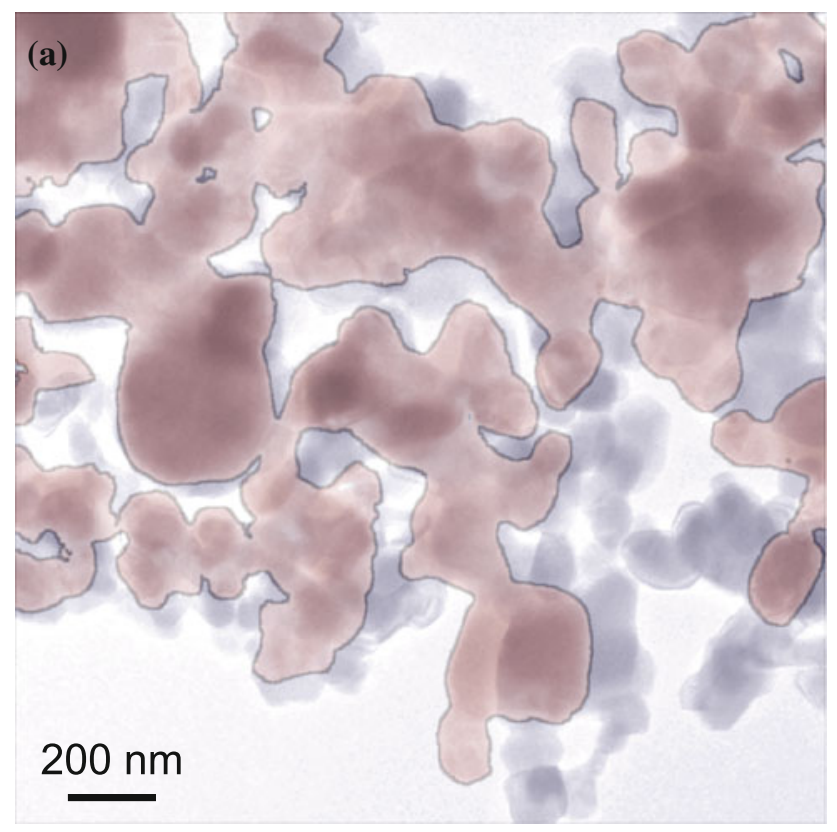

Fig. 9 a Superposition of two bright-field TEM images, showing structural evolution at higher temperature, in the form of a comparison between an initial $\mathrm{NiO}$ grain structure at $300{ }^{\circ} \mathrm{C}$ and a final $\mathrm{Ni}$ microstructure at $615^{\circ} \mathrm{C}$ (after $100 \mathrm{~min}$ above $600{ }^{\circ} \mathrm{C}$, under the conditions illustrated by the red dot in Fig. 1). b Diffraction pattern from $\mathrm{NiO}$ at $300{ }^{\circ} \mathrm{C}$ at the start of the experiment (corresponding to
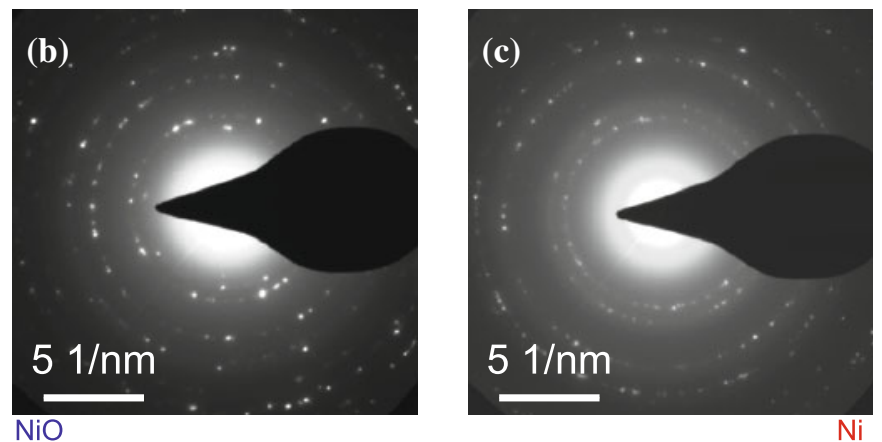

$\mathrm{T}=300^{\circ} \mathrm{C}$

$\mathrm{t}=0 \mathrm{~min}$

(d)

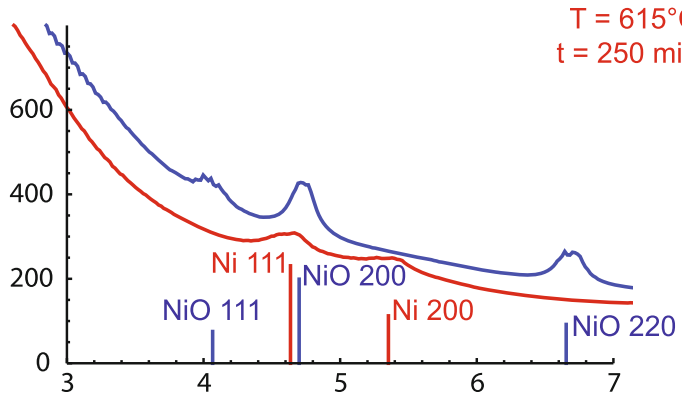

image a coloured in blue). c Diffraction pattern from $\mathrm{Ni}$ after reduction at temperatures up to $615^{\circ} \mathrm{C}$ (corresponding to image a coloured in red). d Radial profiles of the $\mathrm{NiO}$ and $\mathrm{Ni}$ diffraction patterns shown in $\mathbf{b}$ and $\mathbf{c}$, respectively, shown alongside the position of peaks simulated using JEMS software [55]

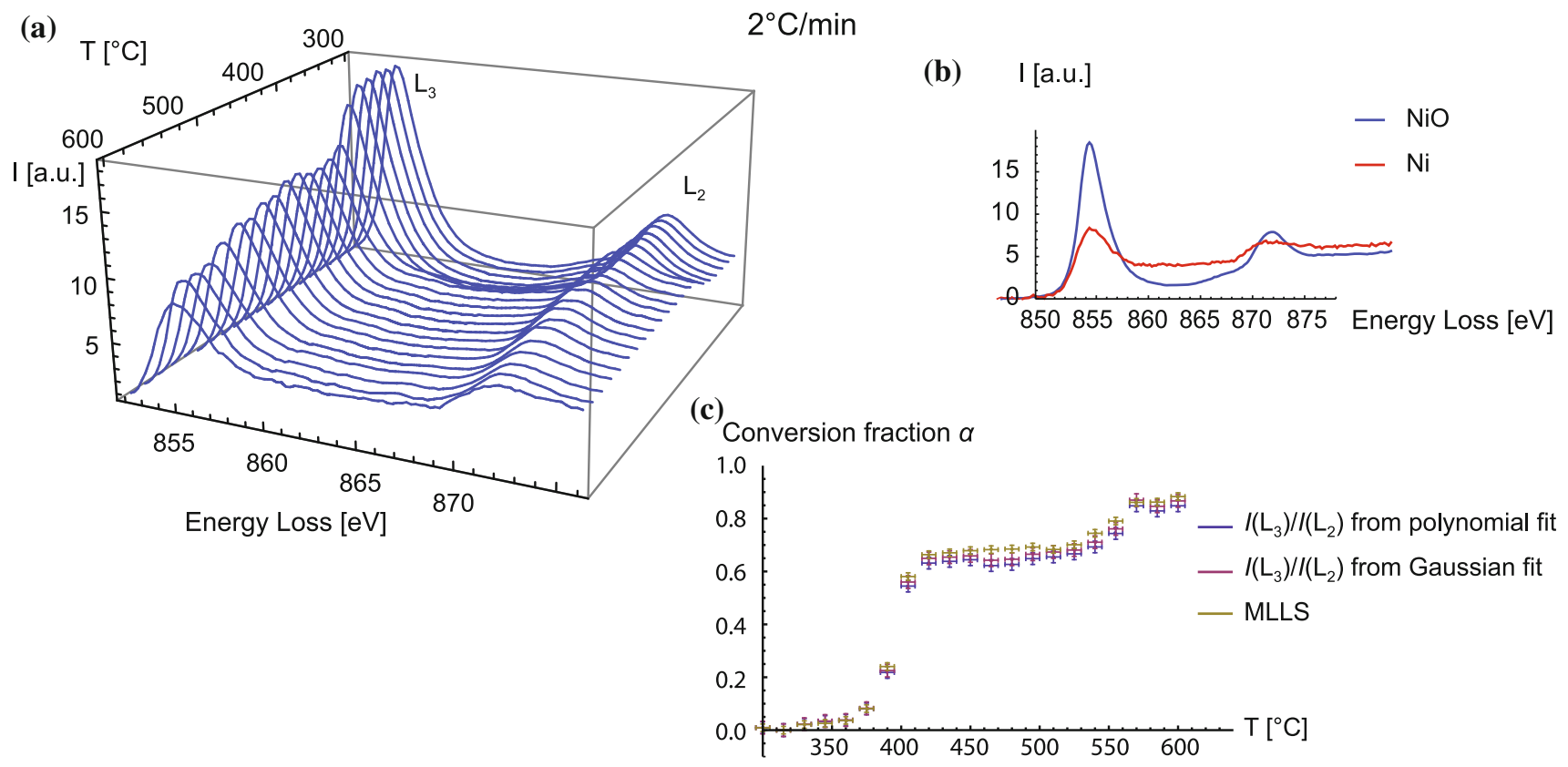

Fig. 10 a Evolution of background-subtracted EEL spectra acquired as a function of temperature for a $2{ }^{\circ} \mathrm{C} / \mathrm{min}$ ramp, with one spectrum acquired every $7.5 \mathrm{~min}$. The $\mathrm{NiO}$ and $\mathrm{Ni}$ experimental reference spectra shown in $\mathbf{b}$ were used to determine $\mathbf{c}$ the reduction kinetics using either the ratio of the $\mathrm{Ni} \mathrm{L}_{3}$ over $\mathrm{L}_{2}$ intensities integrated in $2 \mathrm{eV}$ windows (using polynomial or Gaussian fits for integration) or a multiple linear least squares (MLLS) technique. The vertical uncertainties in $\mathbf{c}$ depend on the technique used to determine $\alpha$ and are obtained using the statistical deviation of the values of $\alpha$ when $\mathrm{NiO}$ is not yet reduced (confirmation by electron diffraction). The horizontal uncertainties are estimated to be $\pm 5{ }^{\circ} \mathrm{C}$ 
Fig. 11 Conversion fraction $\alpha$ obtained from $I\left(\mathrm{~L}_{3}\right) / I\left(\mathrm{~L}_{2}\right)$ ratios and MLLS fitting, plotted as a function of temperature for the three different heating rate experiments. For clarity, error bars are not shown. Fits to the data obtained using Eq. 7 are superimposed onto the measured values

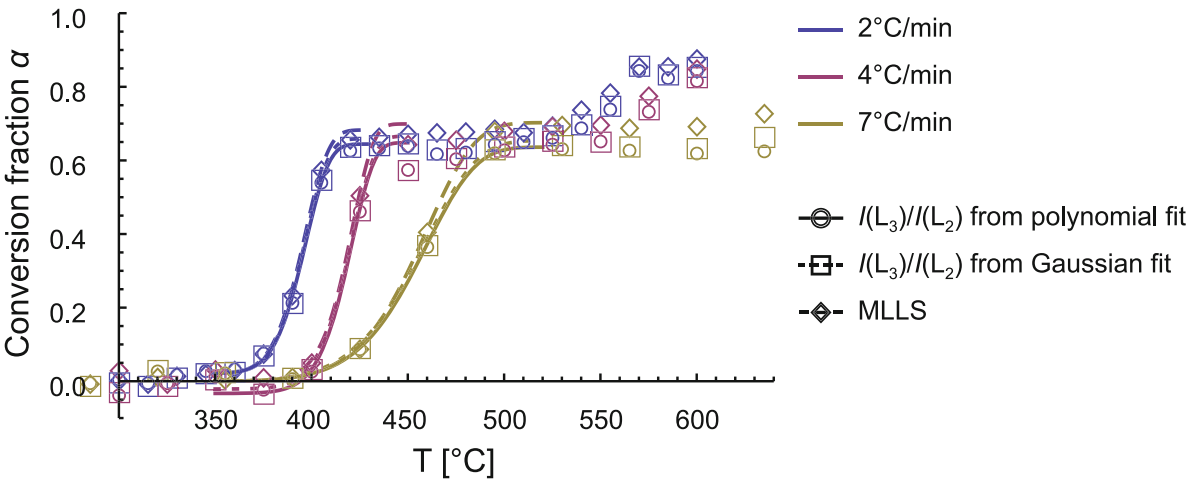

Table 1 Fitting parameters from the analysis of the experimental measurements in Fig. 11, used when applying the Kissinger method to determine the activation energy for the reduction process

\begin{tabular}{lllll}
\hline Method & $\begin{array}{l}T_{\max }\left[{ }^{\circ} \mathrm{C}\right] \\
2,4,7^{\circ} \mathrm{C} / \min \end{array}$ & $\begin{array}{l}\alpha_{\max } \\
2,4,7{ }^{\circ} \mathrm{C} / \mathrm{min}\end{array}$ & $\begin{array}{l}E_{a} \\
{\left[\mathrm{~kJ} \mathrm{~mol}^{-1} \mathrm{~K}^{-1}\right]}\end{array}$ \\
\hline$I\left(\mathrm{~L}_{3}\right) / I\left(\mathrm{~L}_{2}\right)$ using a polynomial fit & $397,421,460$ & $0.38,0.37,0.37$ & 68 & 0.96 \\
$I\left(\mathrm{~L}_{3}\right) / I\left(\mathrm{~L}_{2}\right)$ using a Gaussian fit & $397,421,459$ & $0.39,0.38,0.38$ & 68 & 0.96 \\
MLLS & $397,421,460$ & $0.41,0.41,0.41$ & 67 & 0.96 \\
\hline
\end{tabular}

The values of activation energy obtained using Avrami models A2, A3 and A4 are shown in Table 2 and are similar to those obtained using the Kissinger method above.

\section{Discussion}

Structural evolution of $\mathrm{NiO}$ particles during in situ reduction

$\mathrm{Ni}$ nucleation on $\mathrm{NiO}$ occurs below $400{ }^{\circ} \mathrm{C}$ and can be either epitaxial or non-epitaxial, as seen in Fig. 4. Moreover, small angular differences are observed between $\mathrm{NiO}$ 111 and Ni 111 reflections, corresponding to the formation of two sets of crystallites with clockwise and counterclockwise rotations of $1-3^{\circ}$ compared to the initial $\mathrm{NiO}$ orientation. This process may reduce the $\mathrm{NiO} / \mathrm{Ni}$ interfacial energy, as the $\mathrm{Ni}$ and $\mathrm{NiO}$ unit cell parameters differ by $17 \%$. Random nucleation events are also observed: whilst only a few $\mathrm{NiO}$ grains are initially in diffracting conditions (Fig. 2a), a large number of $\mathrm{Ni}$ grains are observed to diffract with random orientations a few minutes after the start of the reaction, forming a continuous ring in the diffraction pattern (Fig. 2b). Buckett and Marks [57] reported $\mathrm{Ni} / \mathrm{NiO}$ epitaxy during electron beam-induced reduction. Little et al. [58] also observed the formation of both epitaxial and non-epitaxial $\mathrm{Ni}$ domains on $\mathrm{NiO}$ using TEM, with the number of randomly oriented $\mathrm{Ni}$ domains increasing as the reaction proceeded and the number of
Fig. 12 Fits of $\alpha-T$ curves measured for heating rates of 2 , 4 and $7{ }^{\circ} \mathrm{C} / \mathrm{min}$ obtained using $I\left(\mathrm{~L}_{3}\right) / I\left(\mathrm{~L}_{2}\right)$ ratios (with polynomial fits) with Avrami A2, A3 and A4 models

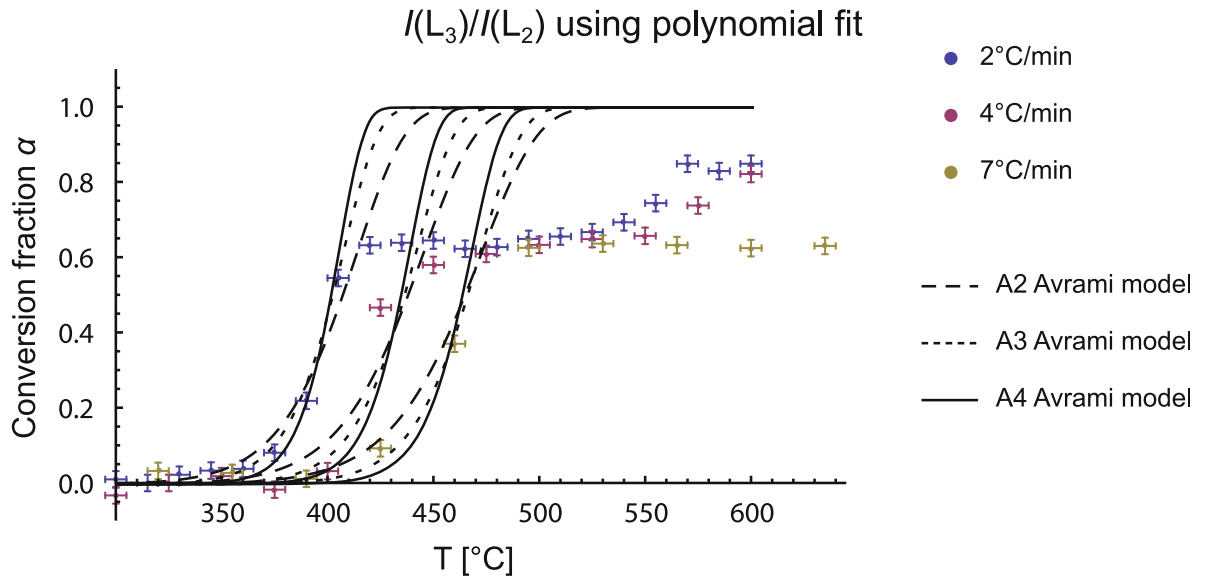


Table 2 Kinetic triplets (Avrami model, activation energy, preexponential factor) used to fit the measured $\alpha-T$ curves for heating rates of 2,4 and $7{ }^{\circ} \mathrm{C} / \mathrm{min}$, obtained using $I\left(\mathrm{~L}_{3}\right) / I\left(\mathrm{~L}_{2}\right)$ ratios (with polynomial fits)

\begin{tabular}{lllll}
\hline Reaction model & $g(\alpha)$ & $\begin{array}{l}A \\
{\left[\mathrm{~min}^{-1}\right]}\end{array}$ & $\begin{array}{l}E_{a} \\
{\left[\mathrm{~kJ} \mathrm{~mol}^{-1} \mathrm{~K}^{-1}\right]}\end{array}$ & $\mathrm{R}^{2}$ \\
\hline Avrami A2 & {$[-\ln (1-\alpha)]^{1 / 2}$} & $5.010^{4}$ & 79 & 0.90 \\
Avrami A3 & {$[-\ln (1-\alpha)]^{1 / 3}$} & $1.110^{4}$ & 71 & 0.92 \\
Avrami A4 & {$[-\ln (1-\alpha)]^{1 / 4}$} & $1.610^{4}$ & 72 & 0.90 \\
\hline
\end{tabular}

epitaxial Ni nuclei decreasing. They stated that the loss of epitaxy results either from the rotation of the $\mathrm{Ni}$ domains as they grow or from the fact that non-epitaxial $\mathrm{Ni}$ regions take a longer time to nucleate, but grow faster when they have formed. Similar rotation angles between $\mathrm{Ni}$ and $\mathrm{NiO}$ were observed in the present study and in the work of Ostyn and Carter who reported angles ranging from 0 to $3.3^{\circ}$ after the ion irradiation-induced reduction of $\mathrm{NiO}$ [59]. The authors explained this loss of coherency by the presence of dislocations around the Ni domains. They also stated that the appearance of cracks around some parts of the $\mathrm{Ni}$ may induce a rotation of those domains, with a repetition of this process inducing a polycrystalline and randomly oriented $\mathrm{Ni}$ structure. In the present study, epitaxy is still observed at $600{ }^{\circ} \mathrm{C}$ when reduction is in an advanced state (Fig. 8). The $\mathrm{NiO} / \mathrm{Ni}$ orientation relationships are therefore likely to be highly sensitive to the precise experimental parameters. Epitaxial relationships are observed here primarily when the heating rate is low, i.e. during experiments performed with long isothermal steps to stabilize thermal drift. The low driving force for nucleation in these nearly isothermal experiments may favour energetically some specific orientation relationships, such as epitaxy.

The Ni domains are three dimensional (Fig. 4) and evolve in time by the movement of interfaces (Fig. 5). Indeed, the irregular movement of the $\mathrm{Ni} / \mathrm{NiO}$ reaction front and/or the merging of $\mathrm{Ni} / \mathrm{Ni}$ domains create heterogeneous and porous $\mathrm{Ni}(\mathrm{O})$ structures (Figs. 3, 6). The reaction is spatially non-uniform, with $\mathrm{Ni}$ seeds forming at different temperatures on different particles (Fig. 6). On some $\mathrm{NiO}$ grains, reduction is observed to proceed through a neighbouring $\mathrm{Ni}(\mathrm{O})$ particle, which had started to react at a lower temperature. The initiation of the reaction is thought to depend on the presence of oxygen surface defects, which may not be distributed homogenously [4]. As the reaction is autocatalytic, it is expected to proceed rapidly once sufficiently large domains have formed.

The presence of Ni nanoparticles at high temperature during the reduction process (Fig. 7) may be associated with the redeposition of $\mathrm{Ni}$ (through the evaporation and recondensation of volatile nickel hydroxide [60-62]) or due to the separation of $\mathrm{Ni}$ nuclei from the bulk [58]. The deposition of a carbon layer in the electron beam may influence these observations, as it may keep the particles separated from the bulk material. Nevertheless, such particles have also been observed in areas that were barely irradiated by the electron beam.

Grain growth and densification of individual particles is observed when the sample is kept at a higher temperature $\left(>550^{\circ} \mathrm{C}\right)$. The system then minimizes its surface energy, with small particles disappearing in favour of larger ones. This reorganization depends on the amount of $\mathrm{NiO}$ present within the $\mathrm{Ni}$, with a reduction in grain growth occurring when the amount of $\mathrm{NiO}$ within the particles is high. Significant densification was observed at $600{ }^{\circ} \mathrm{C}$ for a heating rate of $2{ }^{\circ} \mathrm{C} / \mathrm{min}$ (with the sample nearly fully reduced; Fig. 11), whilst the effect was less significant for the $7{ }^{\circ} \mathrm{C} /$ min sample, in which $\sim 40 \%$ of the initial $\mathrm{NiO}$ was still present. This densification of Ni may also decrease the reaction rate by creating a compact $\mathrm{Ni}$ layer around unreacted $\mathrm{NiO}$ domains. This reorganization of $\mathrm{Ni}$, which occurs at temperatures lower than those at which SOFCs are operated $\left(\sim 800{ }^{\circ} \mathrm{C}\right)$, is detrimental to the connectivity of the Ni catalyst and to the reduction-reoxidation stability of SOFCs [54, 63].

\section{Relationship between reaction kinetics and structural changes}

The Ni content first increases rapidly at temperatures below $400{ }^{\circ} \mathrm{C}$, up to a value of $\alpha$ of $\sim 0.6$ for a heating rate of $2{ }^{\circ} \mathrm{C} / \mathrm{min}$ (Fig. 10). The reaction then slows down in the temperature range $420-520^{\circ} \mathrm{C}$. At higher temperatures $\left(>520{ }^{\circ} \mathrm{C}\right.$ ), the amount of $\mathrm{NiO}$ within the illuminated area slowly tends to 0 . The reaction rate also decreases for heating rates of 4 and $7{ }^{\circ} \mathrm{C} / \mathrm{min}$ when $\alpha$ reaches values of $\sim 0.6$ (Fig. 11). The width of the plateau does not appear to be related to temperature, indicating that this change in kinetics is not associated with solid-state diffusion. The decrease in reaction rate at high values of $\alpha$ appears to be associated with processes that are external to the reaction. As $\mathrm{NiO}$ reduces to $\mathrm{Ni}, \mathrm{H}_{2}$ is consumed and gas shortage may occur in these flow $\left(2 \mathrm{ml}_{\mathrm{N}} / \mathrm{min}\right)$ and pressure (1.3 mbar) conditions inside the reaction chamber $\left(\sim 800 \mathrm{~cm}^{3}\right)$, even if only a few $\mu \mathrm{g}$ of reducible material is dispersed on the TEM grid. As $\mathrm{H}_{2}$ is introduced constantly in the environmental cell, experiments performed at a lower heating rate should allow more time over the same temperature interval to refill the reaction chamber with $\mathrm{H}_{2}$. Therefore, the width of the plateau should decrease with heating rate: an effect that is clearly not observed in Fig. 11. The $\mathrm{H}_{2}$ signal from the mass spectrometer was constant and did not decrease during the reduction 
experiment. It is therefore most probable that the presence and stagnation of $\mathrm{H}_{2} \mathrm{O}$, which is created upon reduction, blocks $\mathrm{H}_{2}$ access to the reactive sites, decreasing the reaction rate at a high conversion fraction (once a sufficient amount of $\mathrm{H}_{2} \mathrm{O}$ has been created, i.e. when $\alpha$ reaches values of $\sim 0.6$ ). The gas flow rate is only $2 \mathrm{ml}_{\mathrm{N}} / \mathrm{min}$ and, in combination with the pumping system, may then not evacuate the product gas efficiently from the $\mathrm{Ni}(\mathrm{O})$ particles. Effects resulting from the presence of water have been observed ex situ by Richardson et al. [64].

The kinetics can be related to the images shown in Fig. 2. The fast reaction that is observed up to a reduced fraction of 0.6 , which occurs in the range $350{ }^{\circ} \mathrm{C}<$ $T<420{ }^{\circ} \mathrm{C}$, creates the porous $\mathrm{Ni}(\mathrm{O})$ structure shown in Fig. 2b. The structure then evolves slowly as the subsequent reaction is blocked. The changes that occur between Fig. $3 b$ and $c$ are mostly associated with the effect of temperature and are only slightly influenced by the chemical reaction. The particles tend slowly towards full reduction at $600{ }^{\circ} \mathrm{C}$, but most of the structural changes are due to the effects of elevated temperature on the reorganization of Ni to reduce its surface energy.

Reduction starts earlier, but at a higher temperature, when the heating rate is increased (Fig. $11,380{ }^{\circ} \mathrm{C}$ at $2{ }^{\circ} \mathrm{C} / \mathrm{min}$ compared to $420{ }^{\circ} \mathrm{C}$ at $7{ }^{\circ} \mathrm{C} / \mathrm{min}$ ), as reported in the literature $[16,17,56]$. The formation of $\mathrm{Ni}$ domains depends on the number of oxygen surface vacancies, which depend in turn on the temperature and on the time for which the sample has been kept at this temperature. Due to the low pressure in the environmental cell, the reaction starts at higher temperatures compared to those found in the literature [13, 23, 56].

In order to determine an activation energy for $\mathrm{NiO}$ reduction, it is assumed that the reaction is not affected by external processes up to a conversion fraction of 0.6. Although the use of ETEM and EELS results in a small number of experimental data points, the activation energy that we calculated using the model-free Kissinger method ( $\sim 70 \mathrm{~kJ} / \mathrm{mol}$ within the range $0<\alpha<0.6)$ corresponds approximately to values found in the literature (10-150 kJ/ mol [13]). Even though the model-fitting technique was also applied to a small number of experimental data points, the advantage of this approach is that it can be correlated directly with ETEM images to determine the most likely reaction model. For example, the images show that the reaction interface is not sharp in an initial $\mathrm{NiO}$ grain and that some particles change shape and shrink upon reduction. A shrinking spherical core model or an Evans-Szekely transformation cannot therefore describe the reduction of these $\mathrm{Ni}(\mathrm{O})$ particles. Based on the EELS data and the images, the nucleation models introduced by Avrami appear to provide a satisfying description of how $\mathrm{NiO}$ is transformed into $\mathrm{Ni}$ [20-22], suggesting that the reaction is controlled by the growth and impingement of Ni domains, which had previously nucleated homogenously on the surface of the $\mathrm{NiO}$. The initial slow reaction rate is linked to the generation of $\mathrm{Ni}$ seeds on the surface, whilst the rate increases at higher temperature as $\mathrm{Ni}$ domains grow and consume NiO. The kinetics deviate from theoretical predictions at values of $\alpha>0.6$ as the reaction is affected by external processes (Fig. 12). The activation energy extracted from the fitted $\alpha-T$ curves is consistent with that obtained by the Kissinger method $(\sim 70 \mathrm{~kJ} / \mathrm{mol})$. The values of the pre-exponential factor $A$ in Table $2\left(\sim 10^{4} \mathrm{~min}^{-1}\right)$ are lower than those reported in the literature $\left(\sim 10^{8} \mathrm{~min}^{-1}\right)[13,23]$. As this parameter is related to the collision frequency, these differences are probably related to the low pressure in the ETEM environmental cell $\left(1.3 \mathrm{mbar}^{\mathrm{H}}\right)$, whereas experiments are generally performed under atmospheric pressure in the literature. It should be noted that only simple physical models are assessed here to identify general trends in the reduction mechanisms, in correlation with images of the resulting structural changes (models listed in [19]).

A porous and irregular $\mathrm{Ni}(\mathrm{O})$ structure similar to that observed in Fig. 2b was previously obtained by reducing a co-sintered $\mathrm{NiO}$-ceramic solid oxide fuel cell anode made from the same commercial $\mathrm{NiO}$ powder as in the present study in the ETEM at $2.5^{\circ} \mathrm{C} / \mathrm{min}$ between 250 and $500{ }^{\circ} \mathrm{C}$ [34]. The reduction mechanisms in the two experiments are different due to the presence of the yttria-stabilized zirconia (YSZ) ceramic phase in the former study. Ni reduction then initiated at NiO-YSZ interfaces at temperatures below $350{ }^{\circ} \mathrm{C}$, by the transfer of oxygen from $\mathrm{NiO}$ to YSZ (i.e. the creation of $\mathrm{O}$ vacancies in $\mathrm{NiO}$ triggered the reduction reaction). The reaction front proceeded towards the centres of the $\mathrm{Ni}(\mathrm{O})$ grains, leaving behind a porous $\mathrm{Ni}$ structure that was related epitaxially to the initial $\mathrm{NiO}$ grain. The shrinking core model describes this reduction mechanism qualitatively, but does not consider the nucleation process, which is fast and uniform at NiO-YSZ interfaces. The reaction rate is controlled by the chemical reaction and the diffusion rates of $\mathrm{H}_{2}$ and $\mathrm{H}_{2} \mathrm{O}$ at $\mathrm{Ni} / \mathrm{NiO}$ interfaces. When the temperature reached values above $400{ }^{\circ} \mathrm{C}$, the free surface of the $\mathrm{Ni}(\mathrm{O})$ grains was reduced directly. In contrast to the present observations, the grains that were examined at $500{ }^{\circ} \mathrm{C}$ were monocrystalline, with the same orientations as the initial NiO grains. The difference to the present observations underlines the importance of the nucleation stage. As the reaction occurs at the $\mathrm{Ni} / \mathrm{NiO}$ interfaces and is autocatalytic, the final $\mathrm{Ni}$ structure and orientation are influenced by how the first Ni domains form (either by fast heterogeneous nucleation at the interfaces as in [34] or by homogenous nucleation as in the present study) and by how these domains then interact. Surface effects and $\mathrm{Ga}^{+}$ implantation due to focused ion beam sample preparation in Ref. [34] may also explain some of the differences. 
In situ reoxidation and reduction of $\mathrm{NiO}$ nanoparticles supported on $\mathrm{SiO}_{2}$ spheres were also studied using ETEM by Chenna et al. [30]. NiO shell structures containing holes in their cores were created upon reoxidation of $\mathrm{Ni}$ nanoparticles in a gas mixture of $\mathrm{CH}_{4}$ and $\mathrm{O}_{2}$. These $\mathrm{NiO}$ nanoparticles were then reduced in situ between 400 and $700{ }^{\circ} \mathrm{C}$ in $\mathrm{H}_{2}, \mathrm{CH}_{4}, \mathrm{CO}$ and/or $\mathrm{H}_{2} \mathrm{O}$. The observed reduction mechanisms were different from those reported here, with $\mathrm{Ni}$ forming inside the porous cores of the $\mathrm{NiO}$ shell structures. The authors stated that oxygen must be present continuously on the surface to react with the reducing gas and that $\mathrm{Ni}$ diffusion along $\mathrm{NiO}$ grain boundaries must be the dominant diffusion mechanism to form Ni cores within $\mathrm{NiO}$ shells. The differences in experimental parameters (gas atmosphere, temperature), $\mathrm{NiO}$ structures (nanoparticles obtained after oxidation of $\mathrm{Ni}$, compared to the present large and dense $\mathrm{NiO}$ particles) and stoichiometry may explain the differences between their experimental observations and the present results. Surface Ni may also have grown in single domains due to the high temperature and small size of the $\mathrm{NiO}$ particles $(<10 \mathrm{~nm})$ and appeared on top of the $\mathrm{NiO}$ cores. Although such effects were not observed in the present study, the use of $\mathrm{SiO}_{2}$ spheres may also play a role in the nucleation process, perhaps as a result of electron beam-induced charging, as $\mathrm{Ni}$ was observed to form close to the silica in their environmental TEM micrographs.

\section{Factors affecting ETEM observations}

ETEM observations may be affected by a number of different factors, such as specimen preparation, specimen geometry and the presence of the high-energy electron beam. The effects of electron beam-induced damage on TEM specimens have been described in detail by Egerton et al. [65]. Buckett and Marks [57] studied the special case of the effects of electron irradiation on $\mathrm{NiO}$; most of the effects described by the authors were also observed here and are listed below, alongside the measures that were taken to reduce their influence on the measurements.

A superstructure (spinel $\mathrm{Ni}_{3} \mathrm{O}_{4}$ according to [57]) forms in the presence of the electron beam in low vacuum conditions at room temperature in ETEM mode (see Supplementary Fig.). This oxidation effect is reversible and may be prevented by only acquiring high-resolution images in $\mathrm{H}_{2}$ at a temperature above $200{ }^{\circ} \mathrm{C}$, at which such a structure is not observed to form in the electron beam.

The presence of hydrocarbons can be problematic for TEM experiments, as they are cracked and deposit on the specimen in the presence of the electron beam. Such a carbon layer may promote reduction, hinder it in the extreme case when a continuous layer forms around $\mathrm{Ni}(\mathrm{O})$ particles and block $\mathrm{H}_{2}$ access to the reaction sites, or trap $\mathrm{Ni}$ crystallites on the specimen surface and separate them from the bulk (see Supplementary Figure). Carbon deposition may be especially severe in STEM mode. Reduction of $\mathrm{NiO}$ was observed to occur at lower temperatures in STEM mode than in TEM mode. The presence of carbon contamination was monitored using EELS and removed by plasma cleaning the sample for $7 \mathrm{~min}$ prior to observations. This decontamination procedure did not appear to modify the reduction stability of the $\mathrm{NiO}$.

Faceting, anisotropic erosion and knock-on damage were also observed when acquiring HRTEM images at a high electron dose (observed within minutes at dose rates higher than $\sim 8000 \mathrm{e}^{-} \mathrm{nm}^{-2} \mathrm{~s}^{-1}$ at a temperature of $365{ }^{\circ} \mathrm{C}$; see Supplementary Figure). Spreading the beam and the use of a small $(70 \mu \mathrm{m})$ condenser aperture reduced these effects, whilst increasing the temperature resulted in more severe irradiation effects. The effect of the highenergy electron beam on heating of the samples may accelerate the reaction locally when images are acquired at high magnification. This effect was not considered to be problematic for the present kinetic experiments, as the electron dose was kept constant, resulting in a similar local temperature increase for all three experiments.

At higher temperature (above $\sim 500{ }^{\circ} \mathrm{C}$ ), nanoparticles from the grid materials ( $\mathrm{Au}$ or $\mathrm{Cu}$ ) may form on the $\mathrm{SiO}_{2}$ film (see Supplementary Figure) [66]. Nanoparticles that are $<2 \mathrm{~nm}$ (most likely $\mathrm{Au}$, indexed by their lattice fringes) were sometimes observed at the step edges of some $\mathrm{NiO}$ particles at lower temperatures $\left(\sim 300^{\circ} \mathrm{C}\right)$. These contamination particles were rare and were then discarded from the analysis. Si nanoparticles may also appear on $\mathrm{SiO}_{2}$ at a higher temperature $\left(\sim 600{ }^{\circ} \mathrm{C}\right)$ [66]. Electron beam-induced charging effects were only observed in high vacuum conditions, resulting in rapid movement of the film and ejection of the supported $\mathrm{NiO}$ particles. This effect was not observed during in situ experiments in the presence of $\mathrm{H}_{2}$ gas in the ETEM.

The use of different sample holders and grid materials ( $\mathrm{Cu}$ or $\mathrm{Au})$ did not affect the observations significantly. As the two furnaces use the same heating technology, the temperature difference between the region of interest and that measured by the thermocouple is therefore similar. Moreover, the characteristic structural changes, such as $\mathrm{Ni}$ nucleation, occurred in the same temperature range for different setups.

As the thermocouple is welded onto the outside of the furnace, the region of interest is at a lower temperature compared to the measured value. This systematic error on the temperature measurements affects the values of the activation energy: The activation energy decreases by $<10 \mathrm{~kJ} / \mathrm{mol}$ if the data are manually offset by an overestimated value of $30{ }^{\circ} \mathrm{C}$ (using both the model-independent technique and the model-fitting procedure). If the 

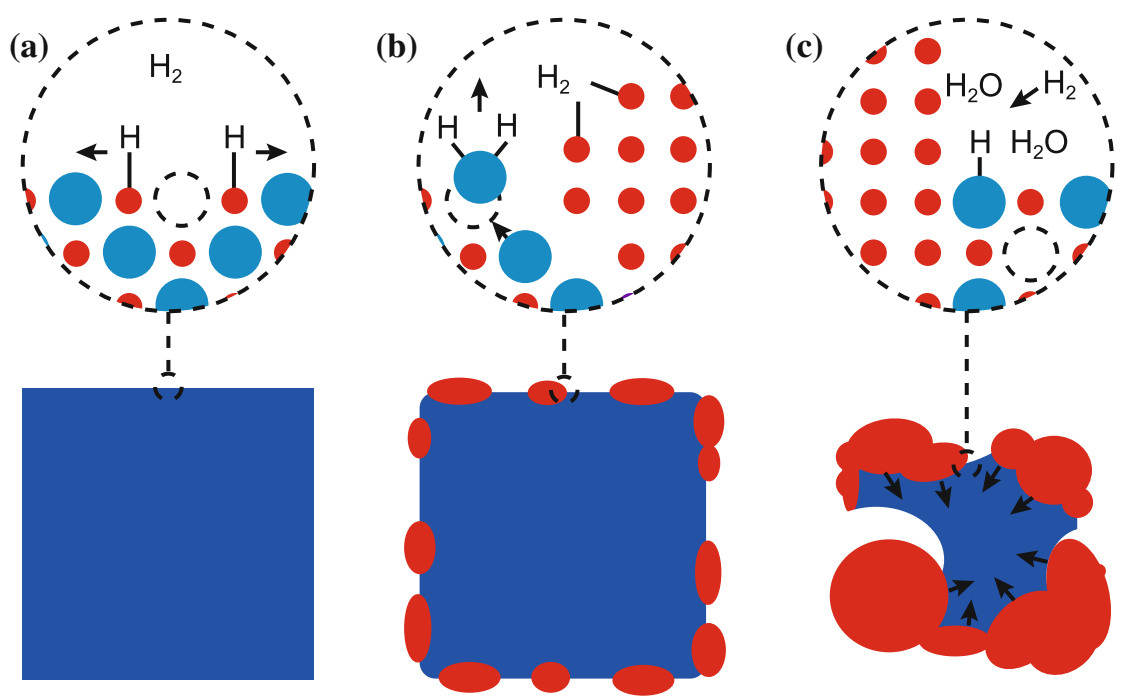

$\because$; O vacancy

$\mathrm{Ni}$

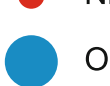

(d)

(e)
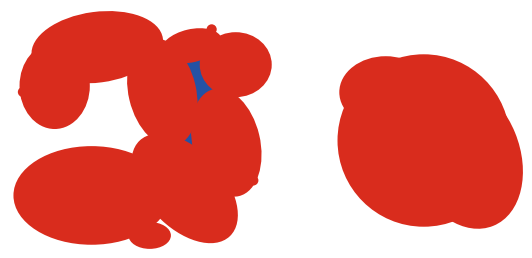

Fig. 13 Model for $\mathrm{NiO}$ reduction and subsequent Ni densification based on the present results

temperature error is set to $-100{ }^{\circ} \mathrm{C}$, the activation energy decreases by $\sim 20 \mathrm{~kJ} / \mathrm{mol}$ using both methods.

In order to rule out the influence of the electron beam on the measurements, areas of interest were compared regularly with regions that had not been illuminated before (as irradiation damage appeared after minutes of illumination rather than seconds). In addition, the electron dose was always kept to a minimum, especially when acquiring images at high magnification, when new regions of interest were also frequently chosen.

\section{Model for $\mathrm{NiO}$ reduction and structural evolution}

Based on the present ETEM observations and on previous studies in the literature, it is possible to propose a structural model that describes $\mathrm{NiO}$ reduction and subsequent structural evolution in the presence of $\mathrm{H}_{2}$. This model is illustrated in Fig. 13. The characteristic steps are as follows. In Fig. 13a, $\mathrm{H}_{2}$ adsorbs and dissociates on two Ni atoms, which are adjacent to an oxygen vacancy [14]. In Fig. 13b, Ni clusters are shown to nucleate into larger domains at temperatures between 350 and $400{ }^{\circ} \mathrm{C}$, with $\mathrm{H}_{2}$ now adsorbing directly onto $\mathrm{Ni}$, with $\mathrm{H}_{2} \mathrm{O}$ desorbing. In Fig. 13c, Ni domains are shown to grow by the movement of interfaces, with pores forming within larger particles, whilst smaller particles shrink to accommodate the volume loss that results from the reduction process to create an irregular structure. Water vapour formed by the reduction process starts to stagnate around the particles and blocks $\mathrm{H}_{2}$ access to the reactive centres. In Fig. 13d, some $\mathrm{NiO}$ becomes trapped within the $\mathrm{Ni}$ structure and the $\mathrm{H}_{2} \mathrm{O}$ prevents further reaction. Finally, when the temperature exceeds $600{ }^{\circ} \mathrm{C}$, larger $\mathrm{Ni}$ grains grow, whilst smaller grains disappear as the system minimizes its surface energy (Fig. 13e).

\section{Conclusion}

Reduction of $\mathrm{NiO}$ particles was performed in a differentially pumped environmental TEM. Images, diffraction patterns and electron energy-loss spectra were acquired to study the structural and chemical evolution of $\mathrm{NiO}$ in the presence of $\mathrm{H}_{2}$ gas. Changes in the shapes of the $\mathrm{Ni} \mathrm{L}_{2,3}$ white lines measured using EELS were used to follow the progress of the reaction and to determine the reaction kinetics for different heating rates. Both model-based and model-independent methods were used to infer a value for the activation energy for $\mathrm{NiO}$ reduction of $\sim 70 \mathrm{~kJ} / \mathrm{mol}$. This value is comparable to previous reports in the literature, providing confidence in the determination of kinetic information using environmental TEM. The results of the model-based fitting procedure and the ETEM observations are consistent with Avrami nucleation models for the reduction process. Possible artefacts resulting from electron irradiation and systematic errors in specimen temperature have been assessed and discussed. The use of environmental TEM to link microstructural changes at the nanoscale with the measured reaction kinetics allows a model for $\mathrm{NiO}$ reduction to be proposed, involving the growth of epitaxial and non-epitaxial $\mathrm{Ni}$ nuclei into larger $\mathrm{Ni}$ domains by the movement of $\mathrm{Ni} / \mathrm{Ni}$ and $\mathrm{NiO} / \mathrm{Ni}$ interfaces.

Acknowledgements Support from the Swiss National Science Foundation is gratefully acknowledged (project 'IN SItu TEm study of reduction and reoxidation of $\mathrm{Ni}(\mathrm{O})$-ceramic composite (INSITE)'). The authors thank D. Laub for TEM sample preparation, G. Lucas for Digital Micrograph plugins, D. Alexander for useful discussions about EELS, and P. Stadelmann for help with Mathematica ${ }^{\circledR}$ programming. The A.P. Møller and Chastine Mc-Kinney Møller Foundation is gratefully acknowledged for their contribution towards the establishment of the Center for Electron Nanoscopy in the Technical University of Denmark. 


\section{References}

1. Kung HH (1989) Transition metal oxides: surface chemistry and catalysis. Elsevier, New York

2. Thomas JM, Thomas WJ (1996) Principles and practice of heterogeneous catalysis. $\mathrm{VCH}$, New York

3. Delmon B (1997) Handbook of heterogeneous catalysis. Wiley $\mathrm{VCH}, \mathrm{New}$ York

4. Furstenau RP, McDougall G, Langell MA (1985) Surf Sci 150(1):55

5. Lescop B, Jay JP, Fanjoux G (2004) Surf Sci 548(1-3):83

6. Hidayat T, Rhamdhani MA, Jak E, Hayes PC (2008) Miner Eng 21(2): 157

7. Hidayat T, Rhamdhani MA, Jak E, Hayes PC (2009) Metall Mater Trans B 40(4):462

8. Hidayat T, Rhamdhani MA, Jak E, Hayes PC (2009) Metall Mater Trans B 40(4):474

9. Hidayat T, Rhamdhani MA, Jak E, Hayes PC (2009) Metall Mater Trans B 40(1):1

10. Minh NQ (1993) J Am Ceram Soc 76(3):563

11. Singhal SC, Kendall K (2003) High temperature solid oxide fuel cell - fundamentals, design and applications. Elseviser, Oxford

12. Benton AF, Emmett PH (1924) J Am Chem Soc 46(12):2728

13. Richardson JT, Scates R, Twigg MV (2003) Appl Catal A 246(1): 137

14. Rodriguez JA, Hanson JC, Frenkel AI, Kim JY, Perez M (2002) J Am Chem Soc 124(2):346

15. Hossain MM, De Lasa HI (2007) AIChE J 53(7):1817

16. Jankovic B, Adnadevic B, Mentus S (2008) Chem Eng Sci 63(3):567

17. Erri P, Varma A (2009) Ind Eng Chem Res 48(1):4

18. Syed-Hassan SSA, Li CZ (2011) Int J Chem Kinet 43(12):667

19. Khawam A, Flanagan DR (2006) J Phys Chem B 110(35):17315

20. Avrami M (1939) J Chem Phys 7(12):1103

21. Avrami M (1940) J Chem Phys 8(2):212

22. Avrami M (1941) J Chem Phys 9(2):177

23. Jankovic B, Adnadevic B, Mentus S (2007) Thermochim Acta 456(1):48

24. Yagi S, Kunii D (1955) Symp (Int) Combust 5(1):231

25. Utigard TA, Wu M, Plascencia G, Marin T (2005) Chem Eng Sci 60(7):2061

26. Szekely J, Evans JW (1971) Metall Trans 2(6):1699

27. L'Vov BV (2010) Russ J Appl Chem 83(5):778

28. Sharma R (2009) Microsc Res Tech 72(3):144

29. Hansen PL, Wagner JB, Helveg S, Rostrup-Nielsen JR, Clausen BS, Topsøe H (2002) Science 295(5562):2053

30. Chenna S, Banerjee R, Crozier PA (2011) Chem Cat Chem 3(6): 1051

31. Yoshida H, Kuwauchi Y, Jinschek JR, Sun K, Tanaka S, Kohyama M, Shimada S, Haruta M, Takeda S (2012) Science 335(6066):317

32. Hofmann S, Sharma R, Wirth CT, Cervantes-Sodi F, Ducati C, Kasama T, Dunin-Borkowski RE, Drucker J, Bennett $P$, Robertson J (2008) Nat Mater 7(5):372
33. Sharma R (2005) J Mater Res 20(7):1695

34. Jeangros Q, Faes A, Wagner JB, Hansen TW, Aschauer U, Van herle J, Hessler-Wyser A, Dunin-Borkowski RE (2010) Acta Mater 58:4578

35. Langford JI, Wilson AJC (1978) J Appl Crystallogr 11(2):102

36. Hansen TW, Wagner JB, Dunin-Borkowski RE (2010) Mater Sci Technol 26(11):1338

37. Sharma R (2012) Micron 43(11): 1147

38. Egerton RF (2009) Rep Prog Phys 72(1):016502

39. Leapman RD, Grunes LA, Fejes PL (1982) Phys Rev B 26(2):614

40. Riedl T, Gemming T, Wetzig K (2006) Ultramicroscopy 106(4-5):284

41. Mitterbauer C, Kothleitner G, Grogger W, Zandbergen H, Freitag B, Tiemeijer P, Hofer F (2003) Ultramicroscopy 96(3-4):469

42. Bonnet N, Brun N, Colliex C (1999) Ultramicroscopy 77(3-4):97

43. Keenan MR, Kotula PG (2004) Surf Interface Anal 36(3):203

44. Gatan (2010) Digital micrograph ${ }^{\mathrm{TM}} 1.84 .1282$ edn. GATAN

45. Pearson DH, Ahn CC, Fultz B (1993) Phys Rev B 47(14):8471

46. van Aken PA, Liebscher B (2002) Phys Chem Miner 29(3):188

47. van Aken PA, Liebscher B, Styrsa VJ (1998) Phys Chem Miner 25(5):323

48. Rez P, Moore ES, Sharma R (2008) Microsc Microanal 14(Suppl. 2): 1382

49. Sharma R, Crozier PA, Kang ZC, Eyring L (2004) Phil Mag 84(25-26):2731

50. Kissinger HE (1957) Anal Chem 29(11):1702

51. Senum GI, Yang RT (1977) J Therm Anal 11(3):445

52. Tarfaoui A (1996) Modelling the kinetics of reduction by temperature programming. Delft University of Technology, Delft

53. Nelder JA, Mead R (1965) The Comput J 7(4):308

54. Faes A, Nakajo A, Hessler-Wyser A, Dubois D, Brisse A, Modena S, Van herle J (2009) J Power Sources 193:55

55. Stadelmann PA (1987) Ultramicroscopy 21(2):131

56. Adnadevic B, Jankovic B (2008) Phys B 403(21-22):4132

57. Buckett MI, Marks LD (1990) Surf Sci 232(3):353

58. Little JA, Evans JW, Westmacott KH (1980) Metall Trans B 11(3):519

59. Ostyn KM, Carter CB (1982) Surf Sci 121(3):360

60. Belton GR, Jordan AS (1967) The J Phys Chem 71(12):4114

61. Du K, Ernst F, Garrels M, Payer J (2008) Int J Mater Res 99(5):548

62. Gubner A, Landes H, Metzger J, Seeg H, Stübner R (1997) Investigations into the degradation of the cermet anode of a solid oxide fuel cells. In: Stimming U, Singhal SC, Tagawa H, Lehnert W (eds) Solid Oxide Fuel Cells V, The electrochemical society, pp 844

63. Sarantaridis D, Atkinson A (2007) Fuel Cells 7(3):246

64. Richardson JT, Lei M, Turk B, Forster K, Twigg MV (1994) Appl Catal A 110(2):217

65. Egerton RF, Li P, Malac M (2004) Micron 35(6):399

66. Zhang Z, Su D (2009) Ultramicroscopy 109(6):766 